\title{
CRENÇAS E SUA RELAÇÁO COM A FORMAÇÃO UNIVERSITÁRIA DE PROFESSORES DE ESPANHOL ${ }^{*}$
}

\author{
Cleidimar Aparecida Mendonça e Silva* \\ LuCielena MENDONÇA DE Lima**
}

\begin{abstract}
Resumo
Este artigo tem como objetivo apresentar as crenças que o $1^{\circ}$ grupo de formandas em LetrasEspanhol (UFG), modalidade licenciatura simples, revelou, por meio de uma sessão reflexiva gravada em dezembro de 2007, em que elas se avaliaram como falantes dessa língua. Na sessão, as participantes puderam refletir sobre as variáveis que, ao longo da graduaçáo, contribuíram para a sua formação como falantes da língua estrangeira (LE). Os dados apontam que as futuras professoras de espanhol ainda mantêm, mesmo após quatro anos de licenciatura, algumas idéias preconcebidas, ligadas ao senso comum, sobre o que seja expressar-se bem em uma LE.
\end{abstract}

Palavras-Chave: Espanhol, crenças, formação inicial.

Beliefs and their connections with pre-service teacher education of Spanish teachers

\section{Abstract}

The aim of this article is to present beliefs that the first group of graduated students in Letters/Spanish (UFG) revealed, through a reflective session recorded in December 2007, when they evaluated themselves as speakers of this language. In this session, the participants reflected on variables that, throughout the course, contributed to their formation as foreign language speakers. The data points that the future Spanish teachers still keep, even after having taken the graduation course for four years, some preconceived ideas related to the common sense, about what expressing well in Foreign Language is.

KEY WORDS: Spanish, beliefs, pre-service teacher education.

\section{INTRODUÇÃo}

Neste artigo, abordamos a conexão que se pode estabelecer entre crenças e formação universitária para o exercício da docência em língua

\footnotetext{
* $\quad$ Parte deste artigo foi apresentada em forma de comunicação oral no V Congresso Brasileiro de Hispanistas UFMG / I Congresso Internacional da Associação Brasileira de Hispanistas, realizado em Belo Horizonte - MG, de 02 a 05/09/2008, com o título "As principais crenças de um grupo de formandas em Letras / Espanhol ao se avaliarem como falantes dessa língua".

** Professora de Espanhol da Faculdade de Letras - UFG. Doutoranda em Letras e Linguística (FL/UFG).

*** Professora de Espanhol da Faculdade de Letras - UFG. Doutora em Filologia Hispânica (Universidad de Oviedo).
} 
espanhola. As onze participantes desta pesquisa eram, na época da coleta de dados, em 2007, concluintes da I turma de licenciandas em Letras/ Espanhol da UFG. A matriz curricular desse curso de graduação foi criada em 2003 com a habilitação simples em Espanhol, duração de quatro anos e regime semestral, portanto, oito semestres.

$\mathrm{Na}$ sessão reflexiva gravada como último compromisso acadêmico desse grupo antes de se formar, as futuras professoras de espanhol revelaram suas crenças, muitas ligadas ao senso comum, sobre os processos de aprendizagem de uma língua estrangeira (LE) em uma instituição formal de ensino. Entre elas destacamos: o fator idade, o temor ao erro, a busca pela correção gramatical, a preocupação com a imersão cultural no país de origem da língua para aprendê-la, entre outras que serão apresentadas ao longo deste trabalho.

A questão em análise se faz importante por possibilitar estender o tema crenças a outras línguas estrangeiras, além do inglês, que possui uma vasta quantidade de pesquisas já publicadas e, também, por envolver uma avaliação criteriosa das licenciandas em Letras/Espanhol sobre como se consideram e se avaliam como falantes e futuras profissionais dessa língua ao concluírem a graduação ${ }^{1}$. Assim, passamos a apresentar uma visão panorâmica sobre o estudo de crenças em nosso país.

\section{As PESQUISAS SOBRE CRENÇAS NO BRASIL}

Ao fazermos uma rápida incursão histórica sobre a pesquisa em crenças na Linguística Aplicada (LA) no Brasil, sem desconsiderarmos sua relevância no exterior, nos baseamos em Barcelos (2004). A autora nos informa que, em meados de 1990, iniciaram-se as investigaçóes nessa área em nosso país. Em 1997, nos Anais do IV Congresso Brasileiro de Linguística Aplicada, quatro trabalhos sobre crenças foram publicados. Entretanto, desde 1995 o tema já figurava nas primeiras dissertaçóes e teses. Ela cita dois trabalhos pioneiros: a pesquisa de Leffa sobre as crenças de alunos de inglês da $5^{\text {a }}$ série e a publicação do livro Dimensóes comunicativas no ensino de línguas, de Almeida Filho, em 1993. Nessa obra, o termo cultura de aprender, que envolve as crenças dos alunos sobre as

1 Os dados da análise foram por mim traduzidos para manter a coerência de um artigo escrito em português. 
formas de se estudar e de se relacionar com a língua-alvo e seus contextos de uso, é apresentado e discutido.

Woods (1993, citado por Silva, 2007) utiliza a metáfora "floresta terminológica" para se referir às crenças, devido à complexa tarefa de investigá-las no contexto de ensino-aprendizagem de uma LE e ao grande número de termos encontrados na literatura tanto em LA quanto em áreas afins, tais como: mitos, imagens, metáforas, teorias pessoais etc. Nesse sentido, Silva (2006) considera que os estudos sobre crenças no Brasil revelam uma preocupação com a construção de um referencial de formação sensível às demandas de nossa sociedade.

Considerando a sala de LE como um espaço social e de interação, entendemos que as crenças das futuras professoras de espanhol sobre como se vêem como falantes desse idioma é fruto de uma entramada teia de fios envolvendo, entre outros fatores, contexto, personalidade e coletividade. Dessa maneira, encontram eco na seguinte definição:

[crenças são] uma forma de pensamento, como construçóes da realidade, maneiras de ver e perceber o mundo e seus fenômenos, co-construídas em nossas experiências e resultantes de um processo interativo de interpretaçấo e (re) significação. Como tal, crenças são sociais (mas também individuais), contextuais e paradoxais. (Barcelos, 2006, p. 18)

Atualmente, a indissociabilidade entre crenças e contexto é inegável, mas nem sempre foi assim. Barcelos (2004) apresenta três momentos marcantes nas pesquisas sobre crenças em LA. No primeiro momento, elas eram descritas por meio de questionários fechados e possuíam um caráter prescritivo (certas ou erradas); no segundo, eram relacionadas às estratégias de aprendizagem, porém o aluno ainda era idealizado e removido de seu contexto; no terceiro momento, finalmente, o contexto passa a ser realmente investigado e as teorias sócio-histórico-culturais se aliam à LA para a problematização das crenças.

Pensando na importância do contexto, característica fundamental do terceiro momento, vejamos como ele delineia o cenário da língua espanhola no Brasil e sua relação com as principais crenças sobre o estudo desse idioma. Antes, porém, faz-se necessário apresentar uma breve discussão sobre os termos Segunda Língua (L2) e LE; Aquisição e Aprendizagem. 
30 Revista Solta a Voz, v. 20, n. 1

\section{CRENÇAS E LÍNGUA ESPANHOLA}

Alguns autores utilizam indistintamente os termos Segunda Língua (L2) e Língua Estrangeira (LE) para se referirem às línguas adquiridas depois da Língua Materna (LM). A equivalência ou diferenciação desses termos acaba dependendo, geralmente, do tipo de pesquisa e dos propósitos da análise de cada investigador. Na literatura da área de formaçáo de professores de espanhol, tanto no exterior como no Brasil, e para os objetivos deste artigo, a língua espanhola é considerada como língua estrangeira. Tal fato se explica porque ela é o resultado de uma atitude intencional do falante em querer aprendê-la, por isso possui um caráter de instrução formal.

O mesmo ocorre com os termos aquisição e aprendizagem. Segundo Krashen (1982), a aquisição é um processo inconsciente e espontâneo, similiar à forma como uma pessoa se apropria de sua LM. A aprendizagem, ao contrário, é um processo consciente e formal, voltado para o estudo de regras gramaticais e para a correção de erros. Por isso se dá em contexto formal de ensino. No caso deste trabalho, o estudo do espanhol é tratado como aprendizagem, mas não deixamos de considerar que existe também aquisição em sala de aula. A opção pelo termo aprendizagem se deve ao fato de as participantes da pesquisa terem tido contato com o idioma somente na universidade, pois nenhuma delas o conhecia antes de nela ingressar.

Ao longo da história do espanhol no Brasil, o idioma experimentou diferentes momentos, de maior ou menor projeção nacional. Entretanto, é a primeira vez que vivencia o processo de implantaçáo de uma lei, a de ${ }^{\circ}$ 11.161/05, que torna sua oferta obrigatória no ensino médio e, por sua vez, gera uma grande demanda por formação de professores. As Orientaçôes Curriculares para o Ensino Médio - Espanhol (Ministério da Educação, 2006), documento que apresenta diretrizes para que esse idioma seja ensinado em âmbito nacional, nos convidam a refletir sobre o lugar que essa língua pode e deve ocupar no processo educativo brasileiro. No documento somos alertados para seu papel social na promoção da cidadania e no reconhecimento da diversidade pela exposição à língua e à cultura do outro.

Nesse cenário, as crenças relacionadas com a língua espanhola no Brasil são propagadas e náo fica imune a elas o futuro profissional que ingressa em um curso de licenciatura. Podemos elencar, de forma breve, as mais comuns, veiculadas e disseminadas na mídia ou presentes nas discussóes em eventos científicos e na literatura sobre o ensino do idioma no Brasil: 
- Língua fácil, língua que não precisa ser estudada. Essa crença se ancora na origem comum entre o português e o espanhol, o latim vulgar. A semelhança entre ambas é realmente grande, pois, entre as neolatinas, são as que guardam maior afinidade entre si. Essa aparente facilidade gera o que Celada (2004) denomina de ilusión de competencia espontánea do falante brasileiro de espanhol, cuja expressão foi e ainda é o portunhol. Almeida Filho (2001a, p.15) explica que "esse 'quase-falar', essa 'criação possível, essa facilidade enfim que o falante de espanhol experimenta [...] mostra uma outra face - o da facilidade enganosa e do conhecimento movediço". Como consequência, prevalece, quase sempre, a sensação de frustração sentida nos estágios intermediário e avançado de ensino. É nessa fase que os alunos costumam perceber que não são capazes de encontrar o que Kulikowski e González (1999) chamam de "la justa medida de una cercanía” entre as duas línguas;

- Espanhol é português mal falado. Essa crença se apóia na aproximação que é feita entre o espanhol e o dialeto caipira do português, variedade discriminada e estereotipada de nossa língua. A modo de exemplo, os verbos "mido", "pido", "preguntar", a inexistência de "ss", "ç", "lh" dão a impressão de que estamos falando e escrevendo "errado" a nossa própria língua. Almeida Filho (2001a) comenta que os aprendizes hispânicos também têm essa mesma sensação ao estudarem português;

- A aprendizagem se dará pelo estudo exaustivo dos falsos amigos. Segundo o linguista norte-americano Richman (citado por Luna, 1998), 90\% das palavras do português têm equivalentes idênticos ou muito semelhantes no espanhol. Podemos nos perguntar, então: falta-nos apenas aprender os $10 \%$ restantes do léxico para conhecer bem o espanhol? Vita (2004) desmistifica essa falsa crença e mostra, em suas pesquisas, que "não há como renegar, no contato entre o Espanhol e o Português, a influência da história somente a uma parte do léxico - às falsas amigas' - e atribuir às 'amigas' um lugar seguro, livre dos mal-entendidos". Nesse sentido, a língua deve ser estudada sistematicamente, como uma realidade linguística complexa e heterogênea;

- A variedade peninsular do espanhol tem mais prestígio que as demais variedades espanholas e hispano-americanas, por isso deve 
ser ensinada. A imagem que prevalece da variedade peninsular, em pesquisas realizadas por Santos (2004) e Irala (2004), é a de que ela é "tradicional", "pura", "formal". Com relação a essa postura, as OCEM (Ministério da Educação, 2006) alertam para o perigo de se propagar uma falsa idéia de homogeneidade do idioma. Dessa forma, ao se ensinar a língua, é preciso mostrar que todas as variedades são ricas e válidas para desfazer estereótipos e preconceitos, orienta o documento.

A seguir, passamos a esboçar algumas crenças reveladas na sessão reflexiva pelas concluintes do curso de Letras/Espanhol sobre o que consideram realmente relevante para se tornarem falantes e profissionais de língua espanhola.

\section{O CONTEXTO E AS PARTICIPANTES DA PESQUISA}

A sessão reflexiva foi gravada com as graduandas de espanhol que tiveram uma matriz curricular que contemplou, entre outras, disciplinas de língua e literatura espanholas, prática oral e escrita no idioma, tradução e variedades sociolinguísticas. Elas ainda participaram de 400 horas de estágio e 400 horas de Prática como Componente Curricular (atividades teórico-práticas realizadas fora da sala de aula). Todas as onze participantes da pesquisa aprenderam espanhol na universidade. Portanto, não conheciam a língua antes de seu ingresso na mesma. Delas, apenas uma visitou, por um curto período, um país hispânico.

As alunas estudaram com professores brasileiros e nativos (um espanhol, uma peruana e uma chilena) e acompanharam sistematicamente o livro didático Avance, nos dois últimos anos da graduação, escrito na variedade peninsular castelhana. Também participaram ativamente de eventos que contaram com a presença de nativos de quase todos os países hispanoamericanos e da Espanha. Além disso, tiveram a oportunidade de discutir, na disciplina Variedades Fonético-Fonológicas hispano-americanas, de forma teórica e prática (análise de filmes e gravaçôes), o tema da variação diatópica (geográfica) do espanhol e receberam, também, alguns nativos em sala de aula para complementação das aulas.

Nesse cenário, a questáo de se considerar como falante da língua estrangeira foi posta em discussão, levando-se em conta os seguintes aspectos: 
sentir-se à vontade para se comunicar o que se pensa e deseja; sentir-se seguro para expressar tudo o que se quer ou precisa; náo sentir vontade de desistir de falar por não encontrar as palavras adequadas ou necessárias; não sentir a sensação, no caso do espanhol, de estar confundindo-o com o português; ter escolhido uma variedade do idioma que o identifique com uma zona geolectal (diatópica) hispânica: Espanha (castelhana, andaluza ou canária) ou Hispano-América (caribenha, centro-americana ou mexicana, chilena, andina ou rio-platense) e saber justificar tal escolha.

Foi proposta, também para a sessão, a reflexão sobre as variáveis que podem haver interferido, ao longo da graduação, na constituição de uma identidade na LE. Entre essas variáveis: professores nativos ou brasileiros; os diversos materiais didáticos utilizados; contatos pessoais ou virtuais com nativos; viagens a países hispânicos; participaçôes em eventos (conferências, congressos, seminários etc.), cursos teóricos (disciplina de variedades sociolinguísticas) etc. Das onze formandas, oito afirmaram que consideram que ainda não possuem uma identidade constituída em língua espanhola. Isso representa um total de $72,72 \%$, um número bastante expressivo para o universo pesquisado. Nas justificativas para esse fato, algumas crenças podem ser explicitadas. Informamos que os dados a seguir não sofreram nenhum tipo de correção linguística para não alterá-los:

\section{A idade é considerada como um fator que pode dificultar a} fluência. Essa crença revela que mesmo tendo conhecimento de que a idade não é um fator determinante para a comunicação na LE, ela ainda é vista como barreira para a plena expressão na língua. Entretanto, se percebe uma consciência da participante ao entender que, com exposição e dedicação constantes, como mostra o excerto a seguir, é possível se aperfeiçoar:

[1]

Sílvia: No sé si los autores están ciertos cuando hablan de la edad, pero es muy difícil. Después de las clases de variedades [Curso de Variedades Fonético-Fonológicas hispano-americanas] sé que conseguimos hacer todos los fonemas, pero hay que practicar, practicar y practicar.

Muitos autores, como Lenneberg (1996 citado por Baralo, 1999), postulam a existência de um período crítico, situado por volta da puberdade, 
que impossibilitaria a aquisição de certos aspectos fonético-fonológicos de uma nova língua. Entretanto, essa autora explica que muitos adultos conseguem um domínio excelente na LE, podendo resolver qualquer situação comunicativa. Também podem se expressar com maior riqueza, correção e adequaçáo que um falante nativo. Isso se deve a muitos fatores, tais como: domínio de um sistema linguístico anterior (o da LM), maturidade, história de vida, conhecimento de mundo, experiências de aprendizagem etc. A crença da participante se apóia na dificuldade de um falante adulto eliminar completamente o sotaque estrangeiro, considerado hoje como algo que não impossibilita uma adequada competência comunicativa.

\section{Passar um tempo em um país de língua espanhola possibilitaria} falar bem o idioma. Essa crença faz parte do imaginário popular, e é amplamente veiculada e divulgada em cursos de idiomas, escolas e universidades. Considera-se que o conhecimento pleno do idioma somente poderá ocorrer em situação de imersão cultural, ou seja, ao se "respirar", o tempo todo, os ares da língua:

[2]

Andrielly: Yo pienso, puede ser una falsa creencia, después de cuatro años será una vergüenza, pero pienso que cuando vaya a un país, tengo muchas ganas, creo que me va a ayudar muchísimo. Creo que unas semanas, unos meses fuera estudiando [...] sería muy bueno, [...] volvería más segura para hablar [...]. No tanto por las correcciones lingüísticas, pero, por el contacto, estar allí todo escrito en español y los nativos e interactuarme. Yo creo que [...] me sentiría más segura, logrando una buena interacción con los nativos, comprando cosas, saliendo por la ciudad y consiguiendo leer las cosas.

Em pesquisa desenvolvida em um curso de Letras/Inglês, em uma universidade federal, Barcelos (1999, p. 169) também pôde constatar que os graduandos sonhavam em estudar no país da língua-alvo, pois "a imagem que o informante tem do exterior é de um lugar idealizado em que se oferece uma aprendizagem sem problemas e sem riscos. Para ele, as situaçóes se encarregaráo de fazer o serviço por ele". Em nossa opinião, essa crença gera muita cobrança e ansiedade por parte do aluno, fazendo com que ele acabe por perder possibilidades reais de contato com a língua mesmo estando em nosso país. A internet facilita distintos contatos virtuais com pessoas de todo o mundo, as universidades investem em interaçóes 
como fontes de pesquisa, existem diversos vídeos no youtube. Além disso, há também filmes, músicas, gravações em áudio e tantas outras situaçōes próximas às interaçôes "reais" com nativos que podem ser aproveitadas tanto em sala de aula como fora dela.

3. Para se expressar com precisão é necessário conhecer e dominar bem o sistema linguístico: o vocabulário, os verbos e os pronomes. Essa crença é também amplamente propagada tanto em cursos livres de idiomas como nos de formação de professores. Acredita-se que o domínio da gramática é condição sine qua non para assegurar uma adequada competência comunicativa:

[3]

Luzza: En cuanto a si tengo voz en la lengua, creo que todavía no [...] Tengo dificultad en hablar, falta de vocabulario [...] de la forma correcta de conjugar los verbos, utilizar de forma correcta los pronombres.

Podemos refletir sobre essa crença à luz da proposta de Hymes (1972) ao introduzir o conceito de competência comunicativa e ampliar a noção de competência linguística de Chomsky. Aquele autor define a competência comunicativa como a capacidade de usar a língua em situaçóes concretas e diversificadas da vida cotidiana. Portanto, o estudo da gramática, sem as regras de uso da língua, é insuficiente. Essa ideia parece não estar totalmente assimilada pela participante, pois ela acaba atribuindo suas limitaçóes comunicativas à falta de domínio do código linguístico.

4. Para se expressar bem é preciso adquirir o ritmo da língua. O que é postulado por essa crença é a noção de que não se pode usar o ritmo da LM para se expressar na língua-alvo. A ideia de se traduzir o que ser quer dizer da LM para a LE, mantendo o ritmo da LM, usando apenas as estruturas e o léxico da LE, é vista como algo negativo.

[4]

Andrielly: Yo creo que la entonación forma parte del acento, porque a veces cuando hablo español es como si yo [...] estuviera pasando del por- 
tugués al español. Me siento así, hablando las palabras en español, la pronunciación en español, pero en el ritmo [...] brasileńo. Y a veces en mi casa yo intento, cuando preparo lo que voy a decir [para uma] presentación, [...] intento dar una entonación distinta, un ritmo a veces más rápido o unos altos y bajos para salir un poquito de eso. Es eso que me gustaría tener [...], hablar así con más ritmo [...]. Por eso creo que sería bueno ir a un país [hispano-falante], [...] para volver hablando con más entonación de acuerdo con la variedad que yo he elegido.

Mey (1998, p. 75) compreende bem essa questão e a justifica: "um sotaque estrangeiro será sempre notado e comentado e, em ocasióes especialmente infelizes, será usado contra o falante". E Revuz (2002, p. 222) ratifica que o que ocorre não é necessariamente uma incapacidade funcional de produzir os sons da nova língua, "trata-se mais de uma incapacidade de jogar de modo diferente com a acentuação, com sons, ritmos e entoaçóes, mesmo conhecidas". Acreditamos que a preocupação da participante não é querer se passar por falante nativa do idioma, crença hoje em dia já superada. Percebe-se que seu desejo é somente "assemelhar-se" ao ritmo da língua-alvo para que sua forma de falar não demonstre tanto um sotaque estrangeiro carregado. Parece que sua real vontade é não ter de traduzir o que se pretende dizer de sua primeira língua para a língua-alvo.

5. Para falar bem é preciso fazer um curso de conversaçáo. Essa crença está associada à ideia de que no curso de licenciatura, pelos muitos compromissos acadêmicos que nele devem ser cumpridos, não é possível adquirir fluência na língua, falta tempo. Assim, resta a alternativa de um curso de conversação fora do curso superior.

[5]

Sílvia: Ahora creo que voy a aprender español [ao concluir a graduação] [...]. Voy a buscar un curso de conversación para sentir más a gusto para hablar porque tengo vergüenza [...]. Eran tantas cosas qué hacer: pruebas, exámenes, trabajos que yo no tenía tiempo algún para practicar [a conversação] en mi casa.

Barcelos (1999) também detectou essa crença em sua pesquisa, revelando que existe, nos alunos, uma alta expectativa por uma aprendizagem em estabelecimentos como cursos livres ou escolas de idiomas. A autora 
lembra que a competência atribuída a esses lugares é dada como certa e, geralmente, não é questionada. $\mathrm{O}$ que pode ser percebido é que à universidade ainda é atribuído somente o papel de formar para a profissão. Assim, parece não estar incluída a fluência na língua. Acreditamos que essa crença se apóia no senso comum, pois atestamos que a universidade é capaz de preparar o profissional e o falante, como ocorreu com esta pesquisadora em sua graduação.

\section{O sotaque brasileiro ao se falar espanhol náo é visto como algo} negativo. Essa crença revela uma tendência atual nos estudos de LA, a de que o professor não nativo tem condiçôes de ensinar a língua com competência e eficácia, desde que bem formado para isso, ou seja, conhecendo as teorias sobre ensino-aprendizagem e áreas afins. Também mostra que o mito da superioridade do professor nativo pode estar sendo superado.

[6]

Maria: Porque no alcanzar un acento nativo no significa hablar correctamente en la lengua. Podemos ser competentes aun con nuestro acento brasileńo y hablar y pronunciar correctamente las consonantes, las vocales y eso creo que tiene que ser trabajado con los alumnos.

[7]

Luzza: Cuando nosotros tenemos contacto [com a língua] y practicamos nosotros mejoramos, si oímos todo el tiempo [...]. A mí me gustó muchísimo el español que tuve de profesoras brasileñas. Creo que hay muchas cosas que los nativos nos pasan, nos traen, pero [...] creo que un profesor brasileño [...] puede preparar muy bien a sus alumnos.

Claro está, pelos excertos anteriores, que o professor brasileiro não tem a obrigação de falar como um nativo. O importante é desenvolver, como observa Almeida Filho (2001b), as características de um bom professor de língua estrangeira, entre elas: um conceito de aprendiz de língua como pessoa em processo de socialização humanizadora; um conceito de língua estrangeira e de linguagem humana; um conceito de aprender outra língua que não a LM; um conceito de ensinar uma nova língua a quem deseja ou precisa dela; um conceito de sala de aula de língua estrangeira (ou de representação do lugar de aprendê-la); um conceito de papéis a desem- 
penhar no processo, seja como aluno, seja como professor. Percebe-se que as futuras professoras revelaram essa preocupação e demonstraram o desejo de estendê-la à sua futura prática pedagógica, ajudando a desmistificar o mito do professor nativo.

7. A escrita oferece mais segurança e possibilidades de se adquirir uma identidade na LE. Essa crença revela que, ao escrever, há uma maior possibilidade de organizar o pensamento, planejar e se aproximar das idiossincrasias do idioma, ou seja, de suas peculiaridades. Isso ocorre porque a escritura é um processo que requer mais tempo e fontes de pesquisas podem ser consultadas.

[8]

Andrielly: En relación con la oralidad y [a escritura], yo tengo más facilidad para escribir [...] en español [...]. Encuentro más mi identidad escribiendo que hablando.

No que tange à segurança da escrita, Revuz (2002) explica que ela representa, por ter caráter de intelectualização e racionalização, uma proteção contra alguma coisa que parece ao mesmo tempo regressiva e transgressiva. $\mathrm{Na}$ oralidade, sente-se mais medo da exposição por esta ter caráter de dinamismo e improvisaçáo, ao passo que a escrita permite a utilização do monitor (Krashen, 1982), espécie de fiscal das produçóes linguísticas que atua na aprendizagem. Esse processo permite maior autonomia, reflexão e reelaboração do que é emitido pelo falante. Assim, a identidade pode ser mais bem constituída.

8. Ter consciência das variedades sociolinguísticas do idioma é condiçáo para nele se expressar bem. A concepção inicial de que o espanhol é uma realidade única, caracterizada pelo prestígio da variedade peninsular, se desfaz quando se entra em contato com as teorias sociolinguísticas que explicam as variaçóes diatópicas do idioma. Esse fato permite compreender que todos os países hispânicos possuem uma norma culta, não havendo, portanto, motivo para discriminaçóes e preconceitos contra as variedades. Várias participantes reconheceram que o curso de Variedades 
Fonético-Fonológicas hispano-americanas foi decisivo para que elas tivessem essa consciência.

[9]

Ana: Sólo en este último año, con el curso de variedades, que tuve conciencia de lo qué es español, de las variedades, variaciones que hay y de todo lo que representa cultura y lengua española.

[10]

Maria: después que [...] hice variedad, la disciplina [...] me ayudó bastante en ese sentido porque además de saber que existían varias regiones diatópicas y que cada hablante tenía su personalidad cuando hablaba [...], empecé a ver que realmente yo me identificaba más por las variedades de América y después por algunos cantantes y por algunas películas. [...]. Mi desafío como profesora será intentar hacer que mis alumnos vean lo que yo sólo conseguí ver en mi último año de facultad.

Nessa perspectiva, Valmaseda (1993), assessor linguístico da Embaixada da Espanha no Brasil na década de 1990, também enfatiza a necessidade de se desfazer mitos sobre o idioma, deixando claro que: qualquer variedade é válida dentro de sua própria norma; que não importa de onde seja o falante e sim se ele emprega bem a língua dentro de sua norma; que essa reflexão pode levar os alunos a valorizarem, inclusive, sua própria língua nativa; que a diversidade léxica não impede a comunicação entre nenhuma variedade e que o aluno pode interessar-se por uma ou outra segundo suas pretensōes ou necessidades. As graduandas, felizmente, tiveram a possibilidade de fazer essa discussão na licenciatura e adotar uma postura consciente, entendendo que, como brasileiras, seu papel é o de "articuladoras de muitas vozes", como defendem as OCEM (Ministério da Educação, 2006).

9. Em situaçáo formal, acadêmica e com assunto que se domina, há mais segurança para falar. Em uma situação específica de aprendizagem formal, o contato com a língua fica restrito à sala de aula, com poucas horas de exposição à mesma e com pouca possibilidade de interação em situaçôes reais de comunicação. Esse fato acaba por restringir o idioma a situaçóes de expressão também formais, em que o que se pretende dizer é preparado previamente, muitas vezes apenas memorizado. 
[11]

Clara: Me siento más a gusto [para falar] cuando es en un contexto formal que tengo la oportunidad de prepararme para hablar y puedo [...] entrenar [...] No me siento a gusto para hablar en contexto informal, pero en contexto formal sí, me siento más a gusto.

Barcelos (1999, p. 166) explica que "apesar de todo o conhecimento e teoria a respeito do movimento comunicativo de ensino de línguas, na prática, os alunos, com raras exceçóes, não têm oportunidades de conviver com modelos comunicativos de ensino de línguas". Tal fato gera a sensação descrita anteriormente, revelando, mais uma vez, que nos processos de aprendizagem de uma LE ainda há certas limitaçóes sentidas por não se ter a oportunidade de vivenciar, realmente, interaçóes significativas. Isso poderia ser superado com contatos com nativos via internet, com filmes, músicas e gravaçóes autênticas, como comentamos na crença número dois.

\section{CONSIDERAÇÓES FINAIS}

Pensando no complexo e intrincado processo que é a aprendizagem de uma LE, principalmente em situação formal, é preciso considerar que estudar uma língua, projetar-se nela, revelar-se, sentir-se como seu falante pleno é algo a ser buscado permanentemente. Não podemos nunca dizer que estamos "prontos", que já sabemos tudo, pois nem em nossa LM é assim. Dessa maneira, a fala de Ana é bastante reveladora: "Aún estoy [...] formándome como hablante y [escritora] en español porque percibo que aún tengo dificultades". Esse depoimento endossa que o processo é contínuo, não é um percurso que se faz de uma hora para outra.

Como no conceito de crenças anteriormente proposto por Barcelos (2004), se pôde verificar a existência de contradiçóes, paradoxos e alguns retrocessos em algumas das crenças reveladas. Entre elas destacamos: a ideia de que a aquisição de toda a língua-alvo somente ocorrerá em situação de imersão cultural, o fato de a idade ser vista como barreira para se expressar bem na língua e a necessidade de se dominar a gramática para se comunicar.

Entretanto, avanços importantes puderam ser percebidos, como a consciência de que o professor brasileiro tem competência para ensinar tão eficazmente quanto o professor nativo e de que as variedades linguís- 
ticas devem ser respeitadas e ensinadas. As contradições demonstradas nas crenças são normais, como seria de se esperar de um grupo heterogêneo, mesmo pequeno. É característica do ser humano, complexo por natureza, e dos contextos únicos e subjetivos que náo podem nunca ser desconsiderados. Ao pensar no que ainda lhes falta para ter voz na LE, as graduandas demonstraram ter consciência de que ainda precisam continuar em processo permanente de formação, transpondo seus próprios limites e avançando rumo à conquista de sua voz identitária na LE.

\section{REFERÊNCIAS}

ALMEIDA FILHO, J. C. P. Uma metodologia específica para o ensino de línguas próximas? In: ALMEIDA FILHO, J. C. P. (Org.). Português para estrangeiros interface com o espanhol. Campinas: Pontes, 2001a.

. O ensino de Línguas no Brasil de 1978. E agora? Revista Brasileira de Lingüistica Aplicada, v. 1, n.1, p. 15-29, 2001b.

BARALO, M. La adquisición del español como lengua extranjera. Madrid: Arco/Libros, 1999.

BARCELOS, A. M. F. A cultura de aprender línguas (inglês) de alunos no curso de Letras. In: ALMEIDA FILHO, J. C. P. (Org.). O professor de língua estrangeira em formação. Campinas: Pontes Editores, 1999.

. Cognição de professores e alunos: tendências recentes na pesquisa de crenças sobre ensino e aprendizagem de línguas. In: BARCELOS, A. M. F.; ABRAHÃO, M. H. V. (Org.). Crenças e ensino de linguas: foco no professor, no aluno e na formação de professores. Campinas: Pontes Editores, 2006.

- Crenças sobre a aprendizagem de línguas, Lingüística Aplicada e ensino de línguas. Linguagem \& Ensino, Pelotas, v. 7, n. 1, p. 123-156, 2004 .

CELADA, M. T. Sobre certas formas de se dizer brasileiro. In: FANJUL, A. P. et al. (Org.). Hispanismo 2002. 3 v. São Paulo: Associação Editorial Humanitas/Associação Brasileira de Hispanistas, 2004.

HYMES, D. H. On communicative competence. In: PRIDE, J. B.; HOLMES, J. (Org.). Sociolinguistics. Harmondsworth: Penguin, 1972. 
IRALA, V. B. A opção da variedade de Espanhol por professores em serviço e pré-serviço. Linguagem \& Ensino, Pelotas, v. 7, n. 2, p. 65-98, jul./dez. 2004.

KRASHEN, S. D. Principles and practice in second language acquisition. Oxford: Pergamon Press, 1982.

KULIKOWSKI, M. Z. M.; GONZÁLEZ, N. T. M. Español para brasileños. Sobre por donde determinar la justa medida de una cercanía. Anuario brasileño de estudios hispánicos, n. 9, p. 11-19, 1999.

LUNA, F. Olá Vizinhos. Revista Veja, São Paulo, 09 de setembro, 1998. Educação, p.106-107.

MEY, J. L. Etnia, identidade e língua. In: SIGNORINI, I. (Org.). Lingua(gem) e identidade. Campinas: Mercado de Letras/São Paulo: Fapesp, 1998.

MINISTÉRIO DA EDUCAÇÃO. Secretaria de Educação Básica. Orientaçôes curriculares para o ensino médio. Linguagem, códigos e suas tecnologias. Cap. 4 Conhecimentos de Espanhol. v. 1. Brasília, 2006. p. 125-164.

REVUZ, C. A. A língua estrangeira entre o desejo de um outro lugar e o risco do exílio. In: SIGNORINI, I. (Org.) Lingua(gem) e identidade: elementos para discussáo no campo aplicado. São Paulo: Mercado de Letras, 2002.

SANTOS, H. S. O papel de estereótipos e preconceitos na aprendizagem de línguas estrangeiras. In: FANJUL, A. P. et al. Hispanismo 2002. São Paulo: Associação editorial Humanitas: Associação Brasileira de Hispanistas, 2004.

SILVA, K. A. Crenças sobre o ensino e aprendizagem de línguas na Lingüística Aplicada: um panorama histórico dos estudos realizados no contexto brasileiro. Linguagem \& Ensino, Pelotas, v. 10, n. 1, p. 235-271, jan./jun. 2007.

- O futuro professor de língua inglesa no espelho: crenças e aglomerados de crenças na formação inicial. In: BARCELOS, A. M. F.; ABRAHÃO, M. H. V. (Orgs.). Crenças e ensino de línguas: foco no professor, no aluno e na formação de professores. Campinas: Pontes Editores, 2006. 
VALMASEDA, M. A. Orientaciones para la enseñanza de la pronunciación en la clase de español como lengua extranjera. São Paulo: Consejería de Educación de la Embajada de España en Brasil/Montevideo: Oltaver, 1993.

VITA, C. P. Os conceitos de falsos amigos, falsos cognatos e heterossemânticos: a discussão de uma sinonímia. Disponível em: www.lle.cce.ufsc.br/congresso/trabalhos_lingua/Claudia\%20Pacheco\%20 Vita.doc. Acesso em: 08 fev. 2008.

Recebido em 17 out. 2008 Aceito em: 16 fev. 2009 